\title{
Imitação e Obra de Arte na Metafísica do Belo
}

\author{
Rosa Gabriella
}

Resumo: No pensamento de Schopenhauer a noção de imitação só pode ser compreendida quando se leva em conta que o artista não procura imitar a natureza a partir dos seu produtos, mas a partir dos seus procedimentos. Além disso, o modelo não é um objeto preexistente e sim uma Idéia, que para ser apreendida depende de um modificação do modo de conhecer do sujeito.

Palavras-chave: imitação - Idéia - desinteresse - beleza - intuição

Viagens costumam ser encantadoras, assim como lugares distantes e desconhecidos ou fatos ocorridos no passado podem parecer fascinantes e misteriosos. Mas por que uma cidade parece mais pitoresca para o estrangeiro que para o nativo, um fato ocorrido no passado mais poético que um acontecimento recente? Segundo Schopenhauer, o encantamento que as viagens podem promover se deve à ausência de vínculos entre o viajante e os lugares que visita, o que explica o fato das obras narrativas e dramáticas transportarem as cenas que representam para outras épocas ou para países distantes. Todo objeto que não pertence à realidade do sujeito favorece a contemplação desinteressada, condição necessária para que haja experiência estética. No entanto, Schopenhauer não vincula o sentimento estético às imagens dos objetos efetivamente representados, mas unicamente às Idéias que podem ser apreendidas em face destes objetos. Assim, ainda que os termos "repetição" (Wiederholung) e cópia (Nachbild) apareçam muitas vezes no Mundo como vontade e representação como sinônimos da obra de arte,

* Mestre em Filosofia pela FFLCH-USP. 
isso não significa que a criação artística deva ser entendida como um processo de reprodução ou duplicação de objetos existentes. Portanto, ao considerar a obra de arte uma cópia ou repetição, Schopenhauer não compartilha da concepção segundo a qual a arte imita a natureza, pois o que importa é que ela seja uma imitação das Idéias concebidas quando o sujeito contempla desinteressadamente o mundo e a vida.

Mas o que significaria imitar uma Idéia concebida num estado de contemplação pura, uma vez que as Idéias não são entidades anteriores à experiência estética? Ora, as Idéias só passam a existir quando o sujeito, ao se desligar da sua própria vontade e do conhecimento submetido ao princípio de razão por alguns instantes, se identifica com o objeto contemplado de um modo totalmente distinto daquele que caracteriza seu conhecimento habitual. Sendo assim, trata-se de uma concepção de imitação intimamente vinculada à transformação do indivíduo em sujeito puro do conhecimento. Segundo esta compreensão de imitação, todo objeto se presta à contemplação estética, porque todas as coisas manifestam a vontade em algum grau da sua objetivação, expressando uma Idéia. A pintura flamenga seria uma prova de que as Idéias podem ser apreendidas a partir das cenas e objetos mais prosaicos, ou seja, de que todo objeto é belo, desde que contemplado de uma maneira puramente objetiva, sem a intervenção da vontade.

Contudo, as coisas podem ser mais ou menos belas, e isso depende do quanto facilitarem a contemplação puramente objetiva. Ainda que o sentimento do belo e a apreensão da Idéia dependam primeiramente do sujeito que considera o objeto ${ }^{1}$, ao afirmar que alguns objetos são mais propícios à contemplação pura que outros, Schopenhauer introduz um critério de beleza que parece depender, ao menos em parte, de características do objeto, sobretudo quando estabelece que certas coisas podem ser qualificadas como "muito belas", por determinarem "a contemplação objetiva de um modo necessário"2. Schopenhauer apresenta duas circunstâncias sob as quais certos objetos podem ser qualificados como "muito belos". Em primeiro lugar, podem receber esta denominação objetos que "exprimem com pureza a Idéia do gênero que neles se manifesta". Graças "à clareza e à precisão da disposição das suas partes", tais objetos tornam mais fácil a passagem (Übergang) da observação comum à contemplação da Idéia. Em segundo lugar, são muito belos os objetos que tornam possível a concepção de uma Idéia correspondente a um grau superior de objetidade da vontade. Neste segundo sentido, a beleza humana ultrapassa todas as outras formas de beleza ${ }^{3}$. 
Uma vez que a beleza humana é considerada a forma superior da beleza, sua representação é o fim mais elevado da arte. No caso das artes plásticas, isso se traduz na representação da forma e da expressão humanas; no caso da poesia, na expressão das ações e do significado da humanidade. Mas deve haver uma forma de arte adequada para expressar cada grau de objetidade da vontade. Partindo deste princípio, Schopenhauer desenvolve uma classificação segundo a qual cabe a cada arte particular exprimir um destes graus, pois cada coisa tem uma beleza que lhe é própria, mesmo "os seres inorgânicos privados de forma" e as propriedades mais gerais da matéria (Stoff). Nela mesma, a matéria não pode ser a representação de uma Idéia pois, de acordo com o Mundo como vontade e representação, ela é essencialmente causalidade. Ora, a causalidade é uma expressão do princípio de razão, portanto, não poderia ser a manifestação de uma Idéia, uma vez que o conhecimento das Idéias é independente desse princípio. Mas a matéria, além de ser causalidade, é o substrato comum a todas as manifestações particulares das Idéias, ou fenômenos e, nesse segundo sentido, forma o liame entre as Idéias e o princípio de individuação, pois todo fenômeno precisa se manifestar pela matéria, que é o suporte das formas e qualidades. Assim, toda coisa particular, enquanto fenômeno de alguma Idéia, é matéria. Nessa medida, a matéria pode ser contemplada de uma maneira estética, e suas qualidades mais gerais, como a gravidade, a coesão, a resistência, a fluidez, ou a mera capacidade de refletir a luz, constituem os graus inferiores de objetidade da vontade.

Facilitar a intuição destas Idéias, que correspondem aos graus mais baixos de objetidade da vontade, é a missão da arquitetura, se considerada exclusivamente do ponto de vista artístico e abstraindo seu aspecto utilitário $^{4}$. Diferentemente das artes plásticas, que fornecem uma cópia (Nachbild), a arquitetura oferece seu objeto para o público diretamente. Nas outras artes tudo se passa como se o criador, ao reproduzir a Idéia que concebeu, emprestasse seus olhos para o público. A arquitetura, quando expõe o conflito entre o peso e a resistência, impedindo que estas duas forças sigam seu curso livremente, apresenta o objeto mesmo, individual e real, e não a cópia As vigas, colunas, abóbadas e pilares são alguns dos recursos que emprega para contrapor o peso das edificações, o qual manifesta a vontade ao pressionálas contra o solo, à resistência, que também é objetidade da Vontade 5 .

A arquitetura tem ainda um outro fim, o de facilitar a apreensão da Idéia da luz que, inversamente ao peso e a resistência, é "o correlato do 
conhecimento intuitivo mais perfeito", a visão. A luz é o meio físico "mais fácil e infalível de chamar a atenção do conhecimento sem despertar a vontade". Algumas impressões sofridas pelos órgãos dos sentidos podem ser chamadas representações por não afetarem, absolutamente, a vontade. São designadas "afecções dos sentidos puramente objetivas" por agirem sobre os órgãos dos sentidos de um modo específico, "produzindo uma excitação tão fraca sobre a sensibilidade destas partes", que "se limitam a entregar ao entendimento os dados a partir dos quais se produzirá a intuição". Dentre estas, as mais perfeitas são as impressões experimentadas pela visão ${ }^{6}$. Assim, Schopenhauer atribui à impressão das cores, sobretudo quando aliadas à transparência, bem como aos reflexos dos raios de sol, o poder de produzir em nós uma enorme e imediata satisfação pura ${ }^{7}$. No entanto, o prazer estético envolvido nesse caso decorre da capacidade que a luz possui para libertar aquele que a contempla do conhecimento submetido à vontade e ao princípio de razão e, conseqüentemente, dos sofrimentos provocados pelo querer. Isso pode ser explicado a partir das duas condições possíveis sob as quais o prazer estético pode se dar. A primeira, subjetiva, consiste no abandono da individualidade, aliado à libertação do jugo da vontade. Estes dois movimentos operam uma transformação na consciência do indivíduo, fazendo com que ele se torne um sujeito puro do conhecimento. $O$ correlato desta transformação, seu elemento objetivo, é a concepção da Idéia platôni$\mathrm{ca}^{8}$. Assim, no caso da arquitetura, o prazer estético ocasionado pela contemplação da luz não se deve à concepção da Idéia, mas ao seu correlato subjetivo, enquanto a concepção das Idéias de peso e resistência corresponde à condição objetiva.

Schopenhauer institui um critério segundo o qual é possivel distinguir a boa arquitetura da má: "cada parte deve estar fixada, não por capricho, mas em função do seu fim e segundo a sua relação com o conjunto". De acordo com este critério, uma coluna retorcida seria de mau- gosto, pois as formas (Formen) das vigas, arcos, cúpulas, dos elementos arquitetônicos de um modo geral, devem explicar- se por si mesmas. Todo ornamento é considerado decoração acessória, perfeitamente dispensável ${ }^{9}$. O princípio que norteia essa exigência de simplicidade é inspirado pelo modo de ação da natureza, que não faz nada em vão, seguindo sempre o caminho mais curto $^{10}$. Observar esta lei, no caso da arquitetura, é se orientar sempre segundo razões puramente construtivas. Schopenhauer reconhece esse procedimento na arquitetura antiga, na qual cada parte revela seu fim mais dire- 
to. Assim, a partir das considerações de Schopenhauer acerca da arquitetura, torna-se mais clara a sua concepção de imitação: se a crítica à imitação da natureza como mera cópia convive com a necessidade de contemplá- la, isso se deve ao fato de que a natureza opera segundo um princípio que, este sim, é modelar.

\begin{abstract}
"Se reconhece, há muito tempo, que cada trabalho determinado por fins humanos, cada artefato e cada edificação, para serem belos, devem ter alguma semelhança com os produtos da natureza. Mas a partir disso surgiu um equívoco. Pensou- se que esta semelhança deveria repousar direta e imediatamente sobre as formas. Porém tal semelhança não deve ser imediata, mas apenas mediata; não deve estar nas formas, mas no caráter (Charakter) destas formas. Os artefatos e edificações não devem imitar a natureza, mas devem ser criados no mesmo espírito que ela. Ou seja, cada coisa e cada parte devem ser tão imediatamente correspondentes, que anunciem aquilo que acontece através deles pelo caminho mais curto e mais fácil. Esta finalidade (Zweckmäßigkeit) é o caráter da natureza" 11 .
\end{abstract}

Schopenhauer discorda daqueles que consideram a regularidade das formas, a proporção e a simetria como elementos fundamentais da arquitetura, pois tais características, enquanto "qualidades puramente geométricas", seriam propriedades do espaço, mas não Idéias ${ }^{12}$. A simetria tem para ele um valor apenas secundário, pois embora ajude a abarcar e a compreender o todo, e a regularidade das formas contribua para a beleza, o essencial da arquitetura, do ponto de vista da contemplação estética, continua sendo a expressão das forças elementares da natureza. A beleza das ruínas seria uma prova do quanto a simetria é dispensável ${ }^{13}$. Mas o fato de tais elementos não contribuírem para a apreensão das Idéias não os torna absolutamente dispensáveis para apreender a essência da própria arquitetura, fora do ponto de vista exclusivamente artístico, que repousa sobre a intuição do espaço. Desse ponto de vista, a regularidade das formas e a relação racional das proporções são fundamentais, e até a simetria contribui para a intuição imediata do conjunto.

O segundo grau de objetidade da vontade corresponde ao reino vegetal e à natureza inconsciente (erkenntnislose Natur). Seus correlatos por excelência são as paisagens, as naturezas mortas, e as representações de in- 
teriores, ruas, ou edifícios. Como por ocasião da contemplação da luz, no caso das naturezas mortas e das pinturas que representam interiores, prevalece o correlato subjetivo da concepção da Idéia, o conhecimento puro e independente da vontade: "a partir do momento em que tomamos emprestados os olhos do pintor experimentamos, por simpatia (Mitempfindung), a mesma serenidade profunda e a completa negação da vontade que lhe são necessárias para absorver tão inteiramente seu ser nos objetos inanimados e concebê- los com um amor tão perfeito, ou seja, de uma maneira tão objeti-

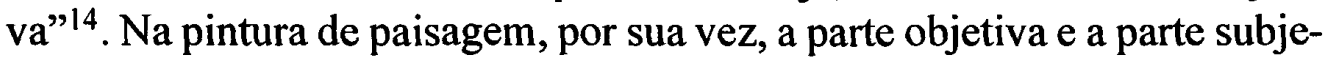
tiva do prazer estético se equilibram.

O terceiro grau de objetidade da vontade corresponderia ao reino animal, e as formas artísticas que as representam são a pintura e a escultura. A partir deste grau, prevalece a parte objetiva do prazer estético. No caso da contemplação do reino animal, apreende- se "o espetáculo da vontade na sua agitação e violência" 15 . Aquilo que o público vê representado é um querer igual ao seu, "a vontade que é una e idêntica em todos os seres", em estado selvagem ${ }^{16}$. Inversamente à natureza vegetal que, embora viva, expressa tranquilidade, paz e satisfação, os animais expressam um estado de agitação, ou mesmo de combate ${ }^{17}$.

Finalmente, o grau mais alto de objetidade da Vontade é a Idéia de homem, e a beleza humana é a sua expressão mais perfeita, sob uma forma intuitiva. A beleza do rosto e da forma (Gestalt) humanos é a representação mais pura e mais clara que podemos ter da Vontade e, ao mesmo tempo, o que nos conduz mais rapidamente a um estado de contemplação pura no qual tanto o elemento objetivo do prazer estético, como o subjetivo, são não apenas intensos como concomitantes pois, "à medida que o elemento objetivo se destaca, é acompanhado pelo elemento subjetivo"18. A beleza como expressão das características da espécie, que já se encontra nos animais ${ }^{19}$, é a beleza tomada no seu "sentido objetivo", na medida em que se exprime exclusivamente por meio da forma (Form), sem manter qualquer relação com o tempo, ou seja, sem envolver o movimento ${ }^{20}$. Uma vez que o corpo humano é um sistema "prodigiosamente organizado de partes completamente diferentes", no qual "cada uma partes está submetida ao todo, mas tem sua vida própria”, apenas excepcionalmente a natureza produz corpos nos quais todas "estas partes estejam subordinadas ao todo e relacionadas entre si de maneira conveniente" e harmoniosa ${ }^{21}$. 
Quando passa a discutir a representação da beleza humana na arte, Schopenhauer introduz o problema da imitação: discorda daqueles que acreditam que a arte imite a natureza. Este problema não se colocava para os graus mais baixos de objetidade da vontade, porque para estes existiam objetos que poderiam levar à apreensão da sua Idéia. Conforme a própria concepção de Idéia, isso não pode significar que estes objetos, enquanto meras representações empíricas, já expõem a Idéia à qual se referem, pois esta só pode resultar de um processo de transformação no sujeito que intui uma Idéia que ainda não estava lá. Esta afirmação pode ser interpretada simplesmente como a constatação de que, quando se trata de intuir os graus mais baixos de objetidade da Vontade, muitos objetos seriam propícios, ao passo que, para intuir a beleza da forma humana, não bastaria olhar para a natureza com olhos desinteressados, porque a natureza jamais teria produzido um homem perfeitamente belo em todas as suas partes. Schopenhauer lembra que, na falta de um modelo digno de ser imitado, muitos autores tentaram solucionar o problema alegando que o artista reúne belezas isoladas, encontradas em diferentes indivíduos, e as combina. Mas essa explicação seria absolutamente ineficiente, pois o problema se mantém: como o artista poderia reconhecer que estas formas são belas?

Schopenhauer propõe uma outra solução: é preciso que o conhecimento da beleza seja, ao menos em parte, a prior ${ }^{22}$. E este conhecimento $a$ priori da beleza humana como objetivação mais perfeita da vontade só é possível porque o próprio homem é Vontade: "Isto é o suficiente para nos dar uma antecipação (Antizipation) real daquilo que a natureza - idêntica à vontade constitutiva da nossa essência - se esforça para apresentar (darzustellen)". No caso do gênio esta antecipação é acompanhada pela reflexão (Besonnenheit) ${ }^{23}$, que faz com que ele seja capaz de, ao entrever a Idéia nas coisas particulares, além de compreender aquilo que a natureza mal "balbuciou", mostrá- la como ele mesmo jamais a viu. É por esse motivo que sua criação ultrapassa a natureza ${ }^{24}$. Esta antecipação, como uma Idéia de belo em parte a priori, é um ideal. Mas, uma vez que tanto o artista como o público precisam recorrer à experiência da natureza, Schopenhauer entende esses dados a posteriori como "esquemas" pelos quais aquilo de que se tinha uma vaga consciência a priori, pode ser verificado. Essa experiência torna possível uma apresentação refletida (besonnener Darstellung) daquele ideal ${ }^{25}$. 
A concepção do belo como um conhecimento parcialmente a priori é bastante modificada nos Suplementos ao Mundo como vontade e representação. Nesse texto, a experiência ganha muito mais relevo, e Schopenhauer introduz uma nova etapa no reconhecimento do belo, ao conceder um papel ao Juízo. Aqui o Juízo produz, a partir da "realidade efetivamente presente ao espírito do artista, de figuras humanas mais ou menos bem- sucedidas em algumas das suas partes", um conhecimento preciso e determinado do ideal de beleza que, até então, seria meramente uma "antecipação confusa". De acordo com esta passagem, a introdução do Juízo implica uma outra modificação em relação ao texto do Mundo como vontade e representação: Schopenhauer passa a considerar que a observação de partes isoladas do corpo contribui para a concepção do belo, o que antes não era admitido. Se os gregos, no Mundo como vontade e representação, eram o exemplo da necessidade de um fundamento a priori para o conhecimento do belo, nos Suplementos eles passam a ser o exemplo de que este conhecimento envolve uma participação do Juízo.

"Os escultores gregos foram muito favorecidos pelo clima e pelos costumes do seu país, pois podiam contemplar diariamente as formas seminuas, ou mesmo inteiramente nuas, dos ginastas. Desse modo, cada membro do corpo desafiava seu senso plástico (plastischen Sinn) a emitir um juízo (Beurteilung) e a compará- lo com o ideal ainda não desenvolvido que traziam na consciência. Assim, não deixavam de exercitar seu Juízo sobre todas as formas e membros, até os menores detalhes, fazendo daquela antecipação, a princípio vaga, do ideal da beleza humana, algo tão claro a ponto de poder ser objetivado nas obras de arte"26.

Entre o conhecimento parcialmente a priori do belo e a experiência, que dá "vida, precisão e extensão" a essa antecipação da beleza, tem lugar um sentido objetivo da beleza humana. Quando submetido à vontade, esse mesmo sentido orienta a escolha do objeto do desejo sexual; mas, quando dissociado da vontade e "a favor de uma inteligência excepcionalmente superior", passa a ser o "sentido artístico que julga" (urteilender Kunstsinn), responsável pelo discernimento da beleza e pela descoberta e exposição da regra $(\mathrm{Norm})$ de todas as proporções do corpo humano ${ }^{27}$. "Este admirável sentido da beleza fez do povo grego o único capaz de descobrir o verdadei- 
ro tipo normal (Normaltypus)da forma humana, estabelecendo definitivamente os modelos de beleza e de graça a serem imitados" 28 .

A beleza como objetividade da vontade no espaço, ou seja, a beleza da forma, não pode revelar inteiramente a vontade que se expressa no homem ou no animal, porque essa vontade mantém, através das ações, uma relação imediata com o tempo. Essa expressão da vontade no tempo revelase nos movimentos e na atitude, pertencendo ao domínio da graça (Grazie). Uma ação "ou corresponde exatamente à vontade que nela se objetiva, sem que nada estranho intervenha, sendo pura e simplesmente a expressão de um ato de vontade determinado, realizado numa dado instante", ou seja, é realizada com graça, "ou produz o resultado contrário" e não podemos the atribuir graça ${ }^{29}$. A graça implica a facilidade, a adequação e o conforto dos movimentos, excluindo tudo o que for supérfluo para a expressão da Vontade, como gestos insignificantes ou posições retorcidas ${ }^{30}$. A proporção entre as partes do corpo e uma constituição regular e harmoniosa são condições para que os movimentos sejam executados com graça, o que equivale a dizer que a graça não existe independentemente do corpo.

Além da beleza da forma - a característica da espécie- e da graça, a representação da figura humana envolve ainda um outro elemento: a representação das características individuais, a saber, o caráter e a expressão. $\mathrm{O}$ caráter individual não deve ser entendido como "algo acidental, uma exclusividade do indivíduo na sua singularidade" ${ }^{31}$, mas como a ênfase em algum dos aspectos da Idéia de humanidade manifestando- se num indivíduo particular. Assim como a beleza da forma humana, o caráter individual deve (soll) ser um ideal, quando colabora para salientar sua significação com respeito à Idéia de humanidade em geral, colaborando para a objetivação desta Idéia. Fora desta perspectiva, a exposição do caráter individual é um retrato (Porträt) de um ser singular, com todos os seus acidentes. Os traços fisionômicos e a constituição física, bem como os estados de alma e as paixões, essencialmente efêmeros, e ainda tudo o que se manifestar pelo rosto ou pelo gesto, como as modificações do conhecer e do querer, são manifestações visíveis do caráter ${ }^{32}$.

Estas modificações do querer e do conhecer dizem respeito à variação da proporção destes dois elementos em cada indivíduo. Se na escala ascendente dos seres vivos o sistema cerebral e os órgãos dos sentidos se tornam mais desenvolvidos à medida que os organismos e suas respectivas necessidades se tornam mais complexos, o homem, que está no topo desta 
escala, além de possuir a faculdade de representação mais perfeita, é também capaz de pensar e refletir, ou seja, representar abstratamente. Isso significa que uma preponderância do conhecer sobre o querer acompanha esta escala ascendente dos seres. Mas, mesmo que se considerasse apenas a espécie humana, a variação da proporção entre estes dois elementos seria muito grande, desde o homem mais tolo até o gênio. A essência da vontade é sempre a mesma: "no menor inseto a mesma vontade existe com toda a perfeição e em toda a sua integridade. Ele quer aquilo que quer tão resolutamente quanto o homem"33. O que muda é o objeto do querer, e este é determinado pelo intelecto.

Na representação da figura humana deve haver um equilíbrio entre a beleza da forma, que sempre tem por referência a espécie e o caráter individual: um não pode encobrir o outro. Se o caráter individual suprimir o caráter específico, o resultado será uma caricatura; se o caráter específico suprimir o caráter individual, o resultado será uma figura insignificante. Em função disso, a escultura, mesmo tendo por objeto principal a beleza da forma, deve destacar algum aspecto particular. Se privilegiasse a beleza específica e omitisse o caráter individual, negligenciaria uma característica essencial da Idéia de humanidade, que é a de manifestar- se em indivíduos que tenham uma significação própria ${ }^{34}$. Por outro lado, se enfatizasse o caráter individual a ponto de suprimir o da espécie, poderia acabar por apresentar algo feio, e mesmo monstruoso. A escultura grega teria conseguido realizar esse feito, pois não exprimiu sua Idéia de beleza uniformemente, mas sob várias formas (Gestalten), que manifestavam caráteres individuais diferentes. "A mesma concepção (de beleza) era sempre apresentada por um outro lado, podendo se manifestar como Apolo, Baco, ou Hércules".

Quando o fim da arte é o de expor a beleza da forma e a graça, o meio mais adequado é a escultura, pois a "beleza é apreendida de uma maneira mais perfeita quando podemos contemplá-la de vários lados"35. Este fim é o que leva o escultor a preferir representar as figuras nuas, ou vestidas de modo que as formas do corpo não sejam encobertas. Em contrapartida, para apresentar o caráter, não é a beleza que está em questão, ele também pode ser exposto também em rostos feios e de corpos fracos. O meio mais adequado para a apresentação do caráter, "tal como este se traduz nos estados da alma, nas paixões, nas ações e reações mútuas do conhecimento e do querer, todas as coisas que unicamente o rosto e os gestos são capazes de reproduzir" ${ }^{36}$, é a pintura. $\mathrm{O}$ fato de mostrar o objeto obrigatoriamente sob 
uma única perspectiva contribui para que ela ponha em relevo as expressões fisionômicas. Além disso, ela tem recursos para representar o olhar, e pode enfatizar os sentimentos através do uso da $\operatorname{cor}^{37}$. A pintura histórica faz exatamente isso. Não apresenta a Idéia de humanidade pela mera forma (Gestalt), como a escultura, mas pelas ações dos homens, pela fisionomia e pelos gestos destes, que revelam as "modificações do conhecimento e do querer"38. A pintura histórica pode cumprir sua missão retratando qualquer tipo de cena, evento ou ação, ela não precisa se referir a um evento histórico determinado ou a um acontecimento descrito pela bíblia. A pintura flamenga seria uma prova de que a vida comum oferece cenas tão significativas quanto estas.

A questão da apreensão da Idéia de humanidade, que surge com a discussão acerca dos quadros históricos, oferece a Schopenhauer a oportunidade para estabelecer uma distinção referente à significação das ações humanas. Toda ação humana teria uma significação exterior, e outra, interior, absolutamente independentes. Para a primeira, a importância da ação é determinada pela perspectiva do princípio de razão suficiente, ou seja, depende das conseqüências desta ação no mundo real, sendo conferida pela relevância do personagem ou do momento histórico representados. A significação exterior não poderia revelar a Idéia de humanidade caso este princípio fosse abstraído. Ela interessa à história, mas não à arte. Para esta apenas a significação interior, que apresenta a Idéia de humanidade, tem importância. Se o princípio de razão suficiente é algo estranho à contemplação pura e, para esta, são irrelevantes as relações que a Idéia concebida possa manter com o mundo real, seja a cena representada uma grande batalha, ou um acontecimento corriqueiro ${ }^{39}$.

A forma artística mais adequada para expressar a Idéia de humanidade é a poesia, embora ela possa ser usada para facilitar a apreensão da Idéia de qualquer grau de manifestação da Vontade, uma vez que a natureza da matéria (Stoff) por ela utilizada, o conceito, é a generalidade. Apenas quando se trata de expressar os graus inferiores da objetidade da Vontade as artes plásticas lhe são superiores. Isso se deve ao fato do reino inorgânico, a natureza inconsciente (erkenntnislose), se manifestar instantaneamente. Como a poesia implica um "desenvolvimento progressivo", adapta- se melhor à expressão dos movimentos, ações e pensamentos do homem.

Schopenhauer reconhece que a experiência pessoal e a história também levam ao conhecimento da natureza humana e chega a entendê- las até 
como condições necessárias para a compreensão da poesia. Mas distinguemse dela porque sempre se referem a indivíduos particulares. A experiência e a história nos mostram "a verdade do fenômeno, e o fenômeno é uma prova sobre a qual essa verdade se apóia"; a poesia nos dá a verdade da Idéia, "que não surge de um fenômeno em particular, mas de todos os fenômenos em geral" " Não cabe ao historiador selecionar, dentre todos os acontecimentos, aqueles verdadeiramente significativos do ponto de vista da Idéia de humanidade. Muito pelo contrário, o critério que governa a escolha de seu objeto é inteiramente determinado pelo princípio de razão, pois são importantes para ele as relações que um determinado fato histórico ou personagem estabelecem com outros fatos, passados ou futuros. O poeta, em contrapartida, escolhe seus personagens e as circunstâncias nas quais estes aparecem segundo o verdadeiro significado da Idéia de humanidade. $O$ poeta precisa, ao criar os gêneros mais objetivos da poesia, obedecer à duas condições: "conceber de uma maneira precisa e completa personagens significativos"; bem como criar situações igualmente significativas, para colocar estes personagens em evidência. Mas a vida e a história não poderiam ser a única fonte dos poetas, pois apenas raramente mostram circunstâncias e personagens tão perfeitos, já que são governadas pelo acaso. Schopenhauer conclui, a partir disso, que o conhecimento da Idéia de humanidade deve ser, ao menos em parte, a priori, assim como o conhecimento do belo nas artes plásticas.

Analogamente ao que se passa em relação ao conhecimento do belo, esse caráter parcialmente a priori do conhecimento da Idéia de humanidade sofre algumas modificações nos Suplementos ao Mundo como vontade e representação. O poeta possui certamente em seu íntimo uma consciência precisa da Idéia de humanidade, mas a experiência serve de esquema (Schema) para esta consciência ${ }^{41}$. Assim como o sentido artístico que julga a bela forma possui um elemento que, quando ligado à vontade, orienta $o$ desejo sexual, o poeta possui um sentido que, quando a serviço da vontade, lhe dá meramente uma experiência de mundo (Weltklugheit) e, quando livre e associado a um excedente de inteligência, constitui a capacidade de exposição objetiva e dramática.

A exposição da Idéia de humanidade pela poesia se dá segundo uma hierarquia, análoga à exposição crescente dos graus de objetidade da vontade pelas diferentes formas artísticas. Segundo esta hierarquia, o gênero lírico seria o gênero mais baixo, por ser o mais subjetivo: "Mesmo um ho- 
mem medíocre pode, quando exaltado devido a uma impressão forte, ou qualquer inspiração súbita, compor uma bela ode pois, para isso, exige- se apenas uma intuição viva dos próprios sentimentos" ${ }^{42}$. A tragédia, por sua vez, seria o gênero mais elevado, perfeito e difícil, por ser o mais objetivo. Ao lado dessa hierarquia que institui entre os diferentes gêneros poéticos segundo a presença da subjetividade do poeta, Schopenhauer estabelece uma correspondência entre a idade do poeta e o gênero que ele está preparado para produzir. Assim, o gênero lírico seria próprio dos jovens, pois "no jovem cada percepção age, antes de mais nada, sobre os sentimentos e a disposição, confundindo- se com eles", enquanto a epopéia e o drama só poderiam ser escritos por poetas mais maduros.

Mas o conhecimento mais elevado que a arte pode proporcionar não é o de alguma Idéia, que é sempre objetidade da Vontade em um grau determinado, e sim o conhecimento do próprio ser da Vontade, que leva àquele que atingiu este conhecimento, a suprimi- la. A tragédia é considerada o gênero poético mais elevado porque corresponde a esse fim. Ao representar o lado terrível da vida, a dor, a angústia, o triunfo do mal, o poder do acaso, está apresentando a vontade lutando contra si mesma. Quando a tragédia mostra os sofrimentos humanos, sejam eles provenientes do acaso ou dos desejos e da ambição do homem, exprime a Idéia de que a Vontade, ainda que seja una a mesma em todos os seres, nos seus diferentes graus de objetivação se manifesta como um conflito eterno entre todos os fenômenos, quando considerados como indivíduos. Schopenhauer interpreta a renúncia do herói "depois de longos combates e sofrimentos aos fins até então ardentemente desejados e perseguidos" como sendo o momento no qual "o conhecimento elevado e purificado pelo próprio sofrimento chega àquele grau em que o mundo exterior não pode mais iludi- lo, onde ele vê claramente o princípio de individuação através do mundo fenomenal"43. Ou seja, em virtude do próprio sofrimento, o herói conhece a natureza da Vontade que está por trás do princípio de individuação. Nesse momento o egoísmo, que decorre deste princípio, desaparece e, com ele, os motivos que o moviam. Esse conhecimento da verdadeira essência do mundo substitui os fins perseguidos pela sua vontade como indivíduo, levando "à resignação, à renúncia, e mesmo à abdicação do querer- viver"44.

O conhecimento proporcionado pelas obras de arte mais perfeitas age também sobre a vontade. Não como o conhecimento comum, que apresenta motivos, mas na medida em que a Idéia concebida por meio da obra "espa- 
Iha sobre o querer sua virtude pacífica, de onde surge a resignação perfeita que é, ao mesmo tempo, o espírito íntimo do cristianismo e da sabedoria hindu; de onde procedem a renúncia a todo desejo, a conversão, a supressão da vontade que engendra a negação do mundo; daí resulta, numa palavra, a salvação (Erlösung)"45. Mas o conhecimento puro atingido pela arte não leva ainda à resignação acabada; não liberta definitivamente do querer viver, mas apenas por alguns instantes. Trata- se de uma consolação provisória. A música constitui uma exceção. Ao contrário de todas as outras artes, ela não é uma cópia (Nachbild) ou repetição (Wiederholung) de uma Idéia, isto é, de uma objetidade adequada da Vontade. A música é completamente independente do mundo fenomenal, "ignora este mundo completamente e poderia, de algum modo, continuar a existir, mesmo que o universo não existisse mais. A música é uma objetidade, uma cópia ( $A b b i l d)$ tão imediata da Vontade quanto o próprio mundo, que é constituído pelos fenômenos das Idéias que se multiplicam dando origem aos objetos individuais" ${ }^{46}$.

Cópia imediata da própria Vontade, a mesma que se objetiva nas Idéias e em todos os seres, a música é a sua objetivação mais perfeita. Como o mundo, ou seja, como o conjunto de todos os seres, ela supõe todos os graus de clareza segundo os quais a Vontade se manifesta. Isso não significa que ela não possa absolutamente ser pensada como uma relação entre representante e representado, ou entre cópia e modelo. Pelo contrário, Schopenhauer admite que "todas as artes possuem esse caráter, e é esta a ação que a música, no seu conjunto, exerce sobre nós". Por acreditar que deve haver uma analogia entre a música e "os fenômenos múltiplos e imperfeitos que formam o mundo visível", Schopenhauer propõe uma explicação que julga satisfatória, ainda que não possa prová- la: a música deve ser considerada a "cópia de um modelo que não pode ser imediatamente representado"47. Esse modelo seria o conflito interminável entre as diferentes manifestações da Vontade. A música seria uma cópia desse conflito, na medida em que uma música absolutamente perfeita do ponto de vista da harmonia é impossível: "toda harmonia se afasta mais ou menos da perfeita pureza. Para dissimular as dissonâncias que lhe são, por essência, inerentes, a harmonia as divide entre os diferentes graus da gama", os quais equivaleriam, nessa relação de representação, aos diferentes graus de objetivação da Vontade ${ }^{48}$. Segundo essa relação, o baixo corresponderia ao reino mineral; o tenor, ao reino vegetal; o alto, ao reino animal; e o soprano, ao homem ${ }^{49}$. 
O entendimento não participa da percepção da música, pois esta se dá exclusivamente "no tempo, e pelo tempo", sem envolver a causalidade, uma vez que "a impressão estética dos sons é produzida unicamente pelo efeito"; nem aparecer no espaço.

A imaginação procura dar uma forma (Gestalt) à música, "se esforça por lhe dar carne e osso, encarná- la num exemplo extraído do mundo real". Essa é a origem das letras das músicas, bem como da ópera. Quando a música se une às palavras, estas sempre têm um papel secundário, uma vez que o efeito dos sons é muito mais forte. $O$ fato da música poder ser acompanhada por palavras seria, inclusive, acidental. Isso porque, do ponto de vista da música, a voz é essencialmente um som, com as mesma características dos sons produzidos por qualquer instrumento. $\mathrm{O}$ fato da generalidade da música dar margem para que a imaginação procure coisas particulares, para dar a ela alguma forma, leva Schopenhauer a esboçar uma semelhança entre a generalidade da música e a generalidade dos conceitos na medida em que, para estes, também é possível encontrar exemplos correspondentes na intuição. Mas a música é sempre uma expressão precisa, pois é um conhecimento intuitivo do próprio ser do mundo, e os conceitos são sempre muito vagos, pois, obtidos a partir da abstração, não se referem a nada que exista realmente. A generalidade da música se assemelha muito mais àquela das figuras geométricas e dos números, que também são gerais, mas são intuitivos e precisos. Ela pode, inclusive, tornar imediatamente perceptíveis as relações numéricas, mas não como a aritmética, que necessariamente recorre a conceitos abstratos.

A música, ao manifestar a vontade em conflito consigo mesma e a tragédia, ao expor o sofrimento no grau mais alto de objetidade, que é o homem, não promovem um sentimento de sofrimento real no público, mas apenas expõem a Idéia desse sofrimento. A arte nunca excita a vontade do público, pois ela não participa absolutamente do estado de contemplação pura. Esse é o motivo pelo qual a música, "sem causar sofrimento real, nos encanta até nos acordes mais dolorosos, e nos causam prazer as melodias mais tristes, quando nos contam, na sua linguagem própria, a história secreta da nossa vontade e de todas as suas perturbações, aspirações, e obstáculos" $" 50$. Pode- se depreender, a partir desta última observação, que toda arte é representação. Mesmo a música, que sem reproduzir as Idéias, é uma manifestação perfeita da própria Vontade, implica uma relação entre alguém que conhece e algo que é conhecido. Mas fica claro que, a partir daquilo 
que Schopenhauer compreende por Idéia, a arte não é a cópia de algo existente, pois a concepção da Idéia é um processo que se dá no interior da consciência do sujeito, ainda que este processo signifique um afastamento da consciência que este sujeito tem de si mesmo como indivíduo, como se ele se fundisse com o objeto.

$O$ fato da experiência estética ter por condição um sujeito puro, ou seja, impessoal, não elimina o caráter imanente que perpassa toda a filosofia de Schopenhauer, pois este conhecimento puro do mundo, que excede o conhecimento necessário à auto-conservação pressupõe, como todo conhecimento, um cérebro e todo um aparato para conhecer, que são condições fisiológicas produzidas pela Vontade. É nesse sentido que a arte, sobretudo nas suas formas mais elevadas, pode ser interpretada como a Vontade que conhece a si mesma, e alguns elementos da estética de Schopenhauer confirmam esta concepção, como o fato da Idéia de Belo ser conhecida parcialmente a priori, por exemplo. Ou seja, a possibilidade para se ultrapassar o conhecimento submetido à Vontade, de vislumbrar, mesmo que apenas por alguns instantes, aquilo que o mundo é, de um ponto de vista diferente daquele que pode ser representado segundo o princípio de razão, é dada pela própria Vontade, uma vez que o excedente de inteligência também é produzido por ela.

\footnotetext{
Abstract: In the Schopenhauer's thought the notion of imitation can be understood just if on take into account that the artist does not aim to imitate the nature through their products, but instead by means of their procedures. Besides, the model is not a preexisting object but an Idea that, to be apprehended, depends of an modification in the subject's way of know.
}

Key-words: Imitation - Idea - desinterest - beauty - intuition 


\section{Notas}

1 Uma vez que a capacidade para apreender as Idéias é conseqüência de uma quantidade de inteligência que ultrapassa aquela necessária para o conhecimento a serviço da vontade.

${ }^{2} W W V, \S 41, S W \mathrm{l}$, p. 298.

${ }^{3}$ Além de considerar certos objetos mais aptos para levar à apreensão das Idéias, a partir do momento em que estabelece que o artista deve ter um fim, o qual consiste no "conhecimento puro, profundo e verdadeiro da natureza e do mundo", Schopenhauer institui, ao mesmo tempo, um critério para julgar as obras, uma vez que passam a ser consideradas obras ruins aquelas que resultam do uso deliberado dos recursos artísticos ignorando este fim $^{3}$.

${ }^{4}$ Ao contrário das outras artes, raramente as obras da arquitetura têm uma destinação unicamente estética. $O$ mérito do artista, nesse caso, consiste justamente em atingir um fim estético (ästhetischen Zwecke) levando em conta outras necessidades. Ele precisa conciliar os fins estéticos e os fins utilitários "determinando qual o gênero de beleza estética e arquitetônica se presta à construção de um templo, de um palácio, ou de um arsenal". Outros fatores, como o clima e o custo da execução, restringem a procura do belo na arquitetura. ( $W W V, \S 43, S W \mathrm{I}, \mathrm{p} .307$ ).

${ }^{5}$ De um modo geral a natureza inorgânica, para Schopenhauer, provoca sentimentos tristes ou opressivos. A água seria uma exceção, tanto pelo fato de ter movimento, o que lhe confere vida, como pelo fato de refletir a luz $(P P, 213, S W V$, p. 502).

${ }^{6}$ Id., $\S 18, S W I$, p. 158. Como explica R. Bayer, "Schopenhauer classificou os sentidos segundo uma ordem de dignidade relativa; eles são mais ou menos dignos conforme forem mais ou menos suscetíveis ao prazer e a dor. A visão, seguida da audição, são os sentidos superiores; o tato, o olfato e o paladar, os inferiores. Somente os sentidos superiores importam no domínio da estética. O tato, o olfato e o paladar são sentidos úteis, mas provocam sensações nas quais se misturam prazer ou dor que, no lugar de favorecerem a intuição pura, estimulam a vontade" (R. Bayer, Histoire de l'esthétique, p. 272).

${ }^{7}$ Suplementos, 30, $S W I I$, p. 484.

${ }^{8} W W V, \S 38, S W I$, p. 285.

9 Id., $\$ 43$, p. 304. 
${ }^{10}$ Schopenhauer enfatiza que a arquitetura deve procurar se orientar segundo o mesmo espírito que a natureza, mas jamais imitar a natureza, tentando reproduzir as formas dos troncos das árvores, ou o do corpo humano, por exemplo ( $W W V$, $S W$ II, p. 533).

"PP, $§ 214, S W V$, p. 503.

${ }^{12}$ Id., p. 532.

${ }^{13} W W V, \S 43, S W$ I, p. 305.

${ }^{14}$ Id., $\S 44$, p. 309.

${ }^{15}$ Ibid., p. 310.

${ }^{16} \mathrm{As}$ Idéias que o reino vegetal manifesta podem ser apreendidas por intermédio da pintura, ou contempladas diretamente na natureza. No caso do reino animal, contemplar diretamente a natureza só leva a conceber a Idéia que o animal manifesta caso ele esteja em liberdade ( $W W V, \S 44, S W 1$, p. 310 ).

${ }^{17}$ Devido a estas características, é mais difícil atingir um estado de conhecimento puro a partir da contemplação dos animais $(P P, 213, S W V$, p. 502).

${ }^{18} W W V$, Suplementos, $\S 45, S W I I$, p. 312.

${ }^{19} \mathrm{Na}$ pintura de animais a, a expressão do traço específico se confunde com a expressão da beleza, porque os animais não têm características individuais, mas apenas características específicas. Assim, "o leão, o lobo, o cavalo ou o touro que melhor exprimem a espécie são sempre os mais belos"(Id., p. 311).

${ }^{20} \mathrm{~A}$ beleza de uma planta corresponde, nesse sentido, ao mesmo gênero de beleza que a beleza humana: a mera forma da planta manifesta totalmente a sua essência (Ibid., p. 315).

${ }^{21} W W V, \S 45, S W I$, p. 312.

${ }^{22}$ Mas não no mesmo sentido em que as formas do princípio de razão são conhecidas a priori. "Estas dizem respeito à forma geral do fenômeno, na medida em que esta forma constitui a condição geral da possibilidade do conhecimento". Já o conhecimento que torna possível a apresentação (Vorstellung) a priori do belo não diz respeito à forma (Form), mas ao conteúdo dos fenômenos; "não ao como, mas à própria natureza dos fenômenos" (Id., p. 314).

${ }^{23}$ Aqui a palavra reflexão (Besonnenheit) é uma metáfora para compreender que o gênio é um reflexo daquilo que conhece e não deve ser confundida com a reflexão abstrata (Reflexion), que é uma operação racional. 
${ }^{24} \mathrm{O}$ fato do conhecimento do belo ser, ao menos parcialmente, a priori, explica como foi possível que os gregos tenham encontrado o arquétipo (Urtypus) da forma humana que se tornou o canône da escultura. “É absurdo imaginar que os gregos tenham descoberto um ideal de beleza humana empiricamente, ao qual teriam chegado a partir de uma síntese de detalhes belos que pudessem ter observado". Ao discutir a poesia, Schopenhauer usa o mesmo argumento: "seria uma erro análogo imaginar que para representar em seus dramas caráteres tão variados, tão verdadeiros, vivos, e profundamente sentidos, tenha bastado a Shakespeare observar sua própria experiência do mundo" (Ibid.).

${ }^{25} W W V, \S 45, S W \mathrm{I}$, p. 315.

${ }^{26} W W V, 36, S W$ II, p. 538.

${ }^{27}$ A lém da mencionada mudança em relação ao texto do Mundo como vontade $e$ representação (1819), vale notar que o juízo, introduzido nos Suplementos (1844) como uma da etapa do reconhecimento do belo, é rejeitado na Critica da filosofía kantiana (1819/44), como já foi mostrado no capítulo II, p. 47.

${ }^{28} W W V, 36, S W I I$, p. 539.

${ }^{29} W W V, \S 45, S W I$, p. 316.

${ }^{30}$ Como no caso da arquitetura, Schopenhauer volta a manifestar, aqui, sua crítica a tudo o que for excessivo, complicado, exagerado, ou inútil. Na análise de cada forma artística esta crítica se repete. A obra mais simples, direta e natural é sempre considerada superior. Isto se deve ao fato da verdadeira inteligência buscar esse caminho para se expressar. Na poesia e na literatura, por exemplo, "o espírito pobre, confuso e excêntrico reveste- se das expressões mais rebuscadas, da retórica mais obscura; procura com isso envolver sua insignificância e sua banalidade em frases difíceis e pomposas" ( $W W V, \S 47, S W I$, p. 323).

${ }^{31} W W V, \S 45, S W I$, p. 317.

${ }^{32} \mathrm{O}$ homem, no conjunto das suas ações está, como todo fenômeno, submetido ao princípio de razão. Mas seu caráter pode ser visto como uma Idéia correspondente a um ato particular da objetivação da Vontade. Este será o seu "caráter inteligível", e o fenômeno desse ato da Vontade será seu "caráter empírico". "O caráter empírico é completamente determinado pelo caráter inteligível, o qual é Vontade, Vontade sem fundamento, Vontade que, como coisa- em- si escapa da forma do princípio de razão, que é forma do fenômeno. O caráter empírico deve, ao longo da sua existência, refletir o caráter inteligível, não pode se comportar de modo diferente daquele exigido pela natureza deste. Todavia essa determinação só se estende para aquilo que é essencial, e não para aquilo que, na existência, é aciden- 
tal. A parte acidental depende da determinação exterior dos eventos e das ações, que são a matéria com a qual o caráter empírico se reveste para se manifestar; são determinados por circunstâncias exteriores que lhe fornecem os motivos, em face dos quais o caráter reage, mostrando sua natureza" ( $W W V, \S 28, S W I$, p. 233).

${ }^{33} W W V$, Suplementos, $\S 19, S W I I$, p. 266.

${ }^{34}$ Todo homem expõe, numa certa medida, uma idéia particular $(W W V, \S 45, S W I$, p. 318).

${ }^{35}$ Uma confirmação de que o fim da escultura é a exposição da beleza, seria o fato de Lessing ter concluído que Laoconte não poderia ter sido representado gritando porque isso seria incompatível com a beleza (Id.).

${ }^{36} W W V, \S 45, S W I$, p. 318.

${ }^{37}$ Para Schopenhauer a escultura sempre exige "senão a beleza perfeita, ao menos a força e a plenitude das formas". Estaria portanto relacionada principalmente à afirmação do querer- viver. Já a pintura, que pode se ocupar também com rostos feios e corpos abatidos, parece estar relacionada à negação do querer- viver. Isso explicaria "porque a escultura foi a grande arte dos antigos, e a pintura a do cristianismo" ( $W W V$, Suplementos, 36, $S W I I$, p. 538).

${ }^{38} W W V, \mathrm{I}, \S 48, S W I$, p. 323. Cabe observar que a pintura histórica "alcançou o apogeu nos séculos XVIII e XIX," e foi "uma disciplinas à qual o ensino acadêmico e o romantismo atribuíram importância quase igual à da pintura sacra" (Marcondes, L. F., Dicionário de termos artísticos, p. 230).

${ }^{39}$ Schopenhauer faz, a propósito, uma apologia da pintura de gênero: "esta pintura produz uma comoção sutil e particular pois, ao fixar numa imagem durável o mundo fugidio, esta eterna sucessão de acontecimentos isolados que compõem para nós todo o universo, a arte produz uma obra que, ao se elevar do particular à Idéia da sua espécie, parece parar o tempo" ( $W W V, \S 48, S W I$, p. 325).

${ }^{40} W W V, \S 51, S W I$, p. 342.

${ }^{41}$ A noção de "esquema" é mencionada por Schopenhauer na primeira edição da Quádrupla raiz do princípio de razão suficiente, onde é rejeitada. Mas é preciso apontar que, nesse texto, era recusada a possibilidade de se estabelecer um esquema entre as imagens, que são intuitivas, e os conceitos, que são abstratos. No caso da poesia, Schopenhauer está sugerindo que a experiência sirva de esquema para a Idéia de belo, ambas pertencentes ao domínio do conhecimento intuitivo.

${ }^{42} W W V, \S 51, S W I$, p. 348. 
${ }^{43}$ Id., p. 353.

${ }^{44}$ A comédia faria exatamente o oposto: é um estímulo para se continuar afirmando a vontade, pois mostra todo sofrimento como algo passageiro; "enuncia que a vida como um todo é boa e incessantemente divertida" (Suplementos, 38, SSW II, p. 562)

${ }^{45} W W V, \S 48, S W I$, p. 327.

46 Ibid., $\S 52$, p. 360.

${ }^{47} W W V, \S 52, S W I$, p. 358.

48 Id., p. 371.

${ }^{49}$ Suplementos, 39, SW II, p. 573.

so Id., p. 579. 


\section{Refèrências Bibliográficas}

1. BAYER. Histoire de l'Esthétique. Paris, Armand Collin, 1961.

2. MARCONDES, L. F. Dicionário de Termos Artísticos. Rio de Janeiro, Pinakotheke, 1988.

3. SCHOPENHAUER, A. Sämtliche Werke. Frankfurt am Main. Suhrkamp, 1993.

4. . "Die Welt als Wille und Vorstellung", Vol I.

5. . "Die Welt als Wille und Vorstellung", Vol II.

6. . De la Quadruple Racine du Principe de Raison Suffisante. Paris, Vrin, 1991. 